\title{
Management of CSOM at a tertiary care hospital
}

\author{
Githin Rajendran ${ }^{1}$, E Balakrishnan², Deepak Thampi Hareendran ${ }^{3}$, Shameem Ahamed SV4*
}

${ }^{1}$ Assistant Professor, ${ }^{2}$ Professor \& HOD, ${ }^{4}$ Associate Professor Department of ENT, Government Medical College, Kannur, INDIA. ${ }^{3}$ Assistant Professor, Department of Surgery, Navodaya Medical College, Raichur, INDIA.

Email: draswinm@gmail.com

Abstract Background: Chronic suppurative otitis media is devided into two types ie. Tubotympanic and Atticoantral. Bacteriologically and etiologically both types are different. Tubotympanic type is usually result of incompletely treated acute suppurative otitis media or recurrent suppurative otitis media. Important feature of this type of disease is the presence of central perforation; however, in atticoantral type perforation is either marginal or attic. A proforma is used for documenting age, sex, address, clinical information, including chief complaints, duration of symptoms, predisposing factors and any previous history of treatment. Other medical history like diabetes mellitus, Hypertension and tuberculosis etc were noted from each patient. Out of 100 patients examined and analyzed, only in $11 \%$ CT scan was advised (5\%) were with cholesteatoma and bony erosion followed by $(3 \%)$ with cavity lesion in addition to the above. Out of 100 patients examined and analyzed, the commonest organism found in the culture is Pseudomonas. Aeruginosa (42\%) followed by Staphylococcus aureus (21\%). The next comes Klebsiella(9\%), Protiums and Coagulase negative Staphylococcus Aureus $(5 \%)$ each and Acinetobacter and E.coli(4\%) each. There is no Growth in (8\%) and (2\%) are commensals.

Keywords: Chronic suppurative otitis media, atticoantral type perforation, Pseudomonas. Aeruginosa

*Address for Correspondence:

Dr Shameem Ahamed SV, Associate Professor, Department of ENT, Government Medical College, Kannur, INDIA.

Email: draswinm@gmail.com

Received Date: 02/12/2019 Revised Date: 30/12/2019 Accepted Date: 18/01/2020

DOI: https://doi.org/10.26611/10161321

\begin{tabular}{|l|l|}
\hline \multicolumn{2}{|c|}{ Access this article online } \\
\hline Quick Response Code: & \multirow{2}{*}{ Website: } \\
\hline & www.medpulse.in \\
\cline { 2 - 2 } & \\
\hline
\end{tabular}

\section{INTRODUCTION}

The assessment and management of chronic suppurative otitis media presents many challenging and fascinating problems. The state of individual ear involved in chronic disease represents the balance established at a particular time between the progression of the debase process on one hand and the healing response within the middle ear cleft on the other. Accordingly the manifestations of chronic suppurative otitis media are extremely variable and there $\mathrm{m}$ ay be any lesion from a small healed deformity of the tympanic Membrane, to a cholesteatoma infiltrating widely throughout the temporal bone ${ }^{1}$. Chronic suppurative otitis media is a disease of multiple aetiology and is well known for its persistence and recurrence inspite of treatment. Chronic suppurative otitis media is a name given to a long standing inflammatory disease affecting mucoperiosteal lining of the middle ear. It is a persistent disease with irreversible sequelae and can proceed to serious intra and /or extra cranial complicatons ${ }^{2}$. Chronic suppurative otitis media is devided into two types ie. Tubotympanic and Atticoantral. Bacteriologically and etiologically both types are different. Tubotympanic type is usually result of incompletely treated acute suppurative otitis media or recurrent suppurative otitis media. Important feature of this type of disease is the presence of central perforation; however, in atticoantral type perforation is either marginal or attic ${ }^{3}$. The widespread use of antibiotics has precipitated the emergence of multiple resistant strains of bacteria which can produce both primary and postoperative infections. The indiscriminate, haphazard and incomplete treatment with antibiotic and poor follow up of patients have resulted in persistence of low grade infections. Changes in the microbiological flora following the advent of sophisticated synthetic antibiotics increase the relevance of reappraisal of the modern day flora. ${ }^{4}$ 


\section{METHODOLOGY}

A cross sectional study was carried out among of Hundred patients with CSOM of all age groups and both sexes, attending the Out Patient Department and those admitted in Otorhinolaryngology wards. Patients were selected randomly for the study. A proforma is used for documenting age, sex, address, clinical information, including chief complaints, duration of symptoms, predisposing factors and any previous history of treatment. Other medical history like diabetes mellitus, Hypertension and tuberculosis etc were noted from each patient. Ear discharge is collected under aseptic precautions in clinically diagnosed cases of CSOM, Excess discharge was mopped out from external auditory canal. Then with the sterile swab, specimen was collected and sent immediately to Department of Microbiology with a requisition for culture and sensitivity. Direct smear examination: In Microbiology Department, a thin smear is made on a clean glass slide and is fixed with $95 \%$ methanol, by pouring one or two drops on the smear and allowed to act for a minimum of 2 minutes or until the methanol dries on the smear. Gram stainig is done for the smears so made and is examined under oil immersion objective to note the various morphological types of bacteria, their nmberr, Gram rection, presence or absence of inflammatory cells and also to note the numbers of squamous epithelial cells in the sample. The discharge is used for inoculation on blood agar, nutrient agar and MacConkey agar plates, All plates were incubated aerobically at $37^{\circ} \mathrm{C}$ and evaluated at 24 hours, 48 hours and 72 hours and the plates were discarded if there is no growth. The specific identification of bacterial pathogens was done based on microscopic morphology, staining characteristics, cultural and biochemical properties using standard laboratory procedures. Antimicrobial susceptibility of the bacterial isolates to be commonly used antibiotics is done by KirbyBauer disc effusion method. Proportions and frequencies are used to find the organisms in the ear discharge and antibiotic sensitivity.

\section{RESULTS}

TABLE 1: Showing quadrants of perforation

\begin{tabular}{ccc}
\hline SL.NO. & SITE & PERCENT \\
\hline 1. & Antero inferior quadrant & 01 \\
2. & Postero superior & 03 \\
3 & Attic & 06 \\
4. & Marginal & 03 \\
5. & Antero superior quadrant + Antero inferior quadrant & 19 \\
6. & Antero superior quadrant + Antero inferior quadrant + Postero superior & 21 \\
& quadrant + postero inferior quadrant & \\
7. & Antero inferior quadrant + Postero inferior quadrant & 40 \\
8. & Postero superior quadrant + postero inferior quadrant & 07 \\
\hline & TOTAL & 100
\end{tabular}

Out of 100 patients examined and analyzed, Most of the patients with CSOM showed central perforation.

Out of 100 patients examined and analyzed, majority of patients with CSOM has moderate size perforation (68\%) followed by large perforation $(15 \%)$

\begin{tabular}{ccc}
\multicolumn{3}{c}{ TABLE 2: Size of perforation } \\
\hline SL.NO. & PERFORATION & PERCENT \\
\hline 1. & Small & 09 \\
2. & Moderate & 68 \\
3. & Large & 15 \\
4. & Subtotal & 03 \\
5. & Total & 05 \\
\hline & TOTAL & 100 \\
\hline
\end{tabular}

Out of 100 patients examined and analyzed, majority of patients with CSOM has Rinne negative on the affected ear (93\%), weber is lateralized to the affected ear $(93 \%)$ and absolute bonne conduction is normal in ( $81 \%)$ in $(7 \%)$ we couldn't access TFT as they were children in lower age group. ABC is reduced in older age group $(12 \%)$.

\begin{tabular}{ccc}
\multicolumn{3}{c}{ TABLE 3: Tuning Fork Tests } \\
\hline SL.NO. & TFT & PERCENT \\
\hline 1. & Rinne & 93 \\
2. & Weber & 93 \\
3. & ABC & 81 \\
4. & Couldn't access & 07 \\
\hline
\end{tabular}

Out of 100 patients examined and analyzed (56\%) of patients with CSOM has mild hearing less (26-40dB) and (29\%) has moderate hearing loss (41-55dB). In (7\%) we couldn't access PTA as they were children of lower age group. 
TABLE 4: PTA

\begin{tabular}{ccc}
\multicolumn{3}{c}{ TABLE 4: PTA } \\
\hline SL.NO. & PTA & PERCENT \\
\hline 1. & Mild & 56 \\
2. & Moderate & 29 \\
3. & Moderately severe & 06 \\
4. & Severe & 02 \\
5. & Couldn't access & 07 \\
\hline \multicolumn{2}{c}{ TOTAL } & 100
\end{tabular}

Out of 100 patients examined and analyzed Only in $(11 \%)$ $\mathrm{x}$-ray was taken $(5 \%)$ of the patients were with bony erosion. $(3 \%)$ were sclerotic. $(2 \%)$ showed both cavity and bony lesion and in (1\%) there was only cavity lesion. In $(89 \%)$ x-ray was not taken.

\begin{tabular}{|c|c|c|}
\hline SL.NO. & $\begin{array}{l}\text { IABLE S: X ray MlastoId } \\
\text { X-RAY MASTOID }\end{array}$ & PERCENT \\
\hline 1. & Not taken & 89 \\
\hline 2. & Sclerotic & 12 \\
\hline 3. & Cavity Lesion & 01 \\
\hline 4. & Bony erosion & 05 \\
\hline 5. & Cavity+ Bony erosion & 02 \\
\hline & TOTAL & 100 \\
\hline \multicolumn{3}{|c|}{ TABLE 6: Showing CT finding in CSOM } \\
\hline \multicolumn{2}{|c|}{ FINDINGS OF CT SCAN } & PERCENT \\
\hline \multicolumn{2}{|c|}{ Not taken } & 89 \\
\hline \multicolumn{2}{|c|}{ Cholesteatoma } & 1 \\
\hline \multicolumn{2}{|c|}{ Sclerotic + cholesteatoma + Bony erosion } & 1 \\
\hline \multicolumn{2}{|c|}{ Cholesteatoma + Bony erosion } & 5 \\
\hline \multicolumn{2}{|c|}{ Cholesteatoma + Bony erosion + cavity lesion } & 3 \\
\hline \multicolumn{2}{|c|}{ Cholesteatoma + cavity lesion. } & 1 \\
\hline & TOTAL & 100 \\
\hline
\end{tabular}

Out of 100 patients examined and analyzed, only in $11 \%$ CT scan was advised (5\%) were with cholesteatoma and bony erosion followed by $(3 \%)$ with cavity lesion in addition to the above. Out of 100 patients examined and analyzed, the commonest organism found in the culture is Pseudomonas. Aeruginosa (42\%) followed by Staphylococcus aureus (21\%). The next comes Klebsiella(9\%), Protiums and Coagulase negative Staphylococcus Aureus (5\%) each and Acinetobacter and E.coli $(4 \%)$ each. There is no Growth in $(8 \%)$ and $(2 \%)$ are commensals.

\begin{tabular}{rcc}
\multicolumn{3}{c}{ TABLE 7: Organism } \\
\hline SL.NO. & ORGANISM & PERCENT \\
\hline 1. & Acinetobacter & 04 \\
2. & Coagulase negative S. aureus & 05 \\
3. & E.Coli & 04 \\
4. & Proteus & 05 \\
5. & Klebsiella & 09 \\
\hline
\end{tabular}

\section{DISCUSSION}

All patients in the present study, has active ear discharge. Most of the patients with CSOM showed central perforation and is comparable with studies below. J. Gulati et al. ${ }^{5}$ in 1969, BM Ahmed et al. in 2003, om a retrospective study of patients with CSOM, most common tympanic membrane perforation is the central type seen in $(60.7 \%)$ of them. Our study showed that, majority of patients with CSOM has moderate size perforation (68\%) followed by large size perforation (15\%). Major population of patients with CSOM in the present study has Rinne negative on the affected ear (93\%). Weber is lateralized to the affected ear (93\%) and ABC is normal in $(81 \%)$. In $(7 \%)$ we couldn't access TFT as they were children in lower age group. ABC is reduced in older age group $(12 \%)$. Pure tune audiometry done in the present study showed $(56 \%)$ of the patients with CSOM has mild hearing loss $(20-40 \mathrm{db})$ and $(29 \%)$ has moderate hearing has $(41-55 \mathrm{dh})$, in (7\%) we couldn't access PTA as they were children in the lower age group. The nasal examination in of patients with CSOM showed normal external appearance in $(73 \%)$. There was adenoid hypertrophy in $(26 \%)$ on posterior rhinoscopic examination and in (8\%) it is not done as they were children in lower age group. None of them had paranasal sinus tenderness. The prevalene of URTI could probably be due to deviated nasal septum, which is seen mostly in older age group and adenoid hypertrophy, which is seen mostly in children and is comparable with studies below. J. Gulati et al. ${ }^{5}$ in 1969, Poorey V.K. et al. ${ }^{6}$ in 2000 and BM Ahmad et al. ${ }^{42}$ in 2003 suggested that the disease typically follows viral infection of URTI which leads to pyogenic infection or is an associated symptoms. In the present study, the examination of Oral Cavity, Oropharynx and throat were with in normal limits. Majority of the patients with CSOM in the present study are with TTD $(88 \%)$ and $(12 \%)$ were with AAD and is comparable with study below. Kabir $\mathrm{MS}^{7}$ in 2012. In a study Pattern of CSOM, among 110 patients (90\%) patients presented with TTD and $10 \%$ patients presented with AAD. The mastoid X-ray of the patients with CSOM in our study showed that, $(5 \%)$ were with bony erosion. (3\% were sclerotic, $(2 \%)$ showed both cavity and bony erosion and in (1\%) there was only cavity lesion. CT was not taken in majority of cases, it was advised mainly for AAD. Out of these, (11\%) showed Cholesteatoma sac with bony erosion, cavity lesion and sclerosis of the mastoid. According to our study, the Gram staining of the organism isolated showed Gram negative organisms in majority of the case $(60 \%)$ and Gram positive organisms in $(30 \%)$. $\mathrm{P}$. aeruginosa is the predominant organism followed by Klebsiella and is comparable with studies below. Poorey V.K. et al. ${ }^{6}$ in 20002 suggested that, Pseudomonas is the predominant organism followed by Klebsiella. Tammoy Deb et al. ${ }^{8}$ in 2012. In a study of the Bacteriological Profile of CSOM in Agartala, suggested that gram negative bacteria is the 
commonest involved in CSOM in this part of north east India. In the present series of 100 patients with CSOM, the commonest organism found in the culture is P.aeruginosa (42\%) followed by S.aureus (21\%). The next Comes Klebsiella (9\%), Proteus and CNSA (5\%) each and Acinetobacter and E.coli (4 each. There is no Growth in $(8 \%)$ and $(2 \%)$ are commensals and is comparable with studies below. Fliss DM et al. ${ }^{9}$ in 1992, found that P. aeruginosa was the most common isolate in 48 cases (38\%) it was the only isolate. Enteric bacilli, S.aureus, Streptococci and H. influenza were also common. Atanu Nandy et al. ${ }^{10}$ in 1991 , came to a conclusion in a bacteriological study CSOM.A total of 146(77.6\%) cases of CSOM (CSOM), comparing of 77 males and 69 females in different age groups were studies. Out of a total 192 isolates. pseudomonas sp.manked highest with (43.8\%) incidence followed by staph. Pyogenes (18.2\%), proteus $\mathrm{dp}(12 \%)$, klebsiella $\operatorname{sp}(7.3 \%)$ and Diphtheroids(6.7\%). Erkan M et al. ${ }^{11}$ in 1994, in a study of Bacteriology of CSOM in 183 patients P.aeruginosa was recoverd from 68 patients, other aerobes commonly recovered include S.arureus and K.pneumonia. RS Greval et al. ${ }^{11}$ in 1996, in study on Bacteriological patterns of CSOM, in Ludhiana, concluded that series of 300 cases of CSOM encountered in Dayanand Medical College and Hospital, Ludhiana was surveyed for type specificity to determine latest trends of bacterial prevalence in Ludhiana, Punjab, pseudomonas staphylococcus and proteus head the list. Gupta V et al. ${ }^{12}$ in 1998, CSOM: in a study of 334 adult patients with CSOM, the commonest organism isolated were P. aeruginosa while $\mathrm{S}$. aureus were found in CSOM with cholesteatoma. Indudharam R. et al. ${ }^{13}$ in 1999, in his tudy on Antibiotics in CSOM and Bacteriological study, 382 swabs examined the major organism isolated were P.aeruginosa (27.2\%) followed by S.aureus (23.6\%). Kamran Iqbal et al. ${ }^{14}$ in 2011, in a study on microbiology of CSOM suggested that, From 190 specimens, $174(91.6 \%)$ were positive, and $16(8.4 \%)$ culture negative. There were $167(87.9 \%)$ bacterial isolates and 7(3.7\%) fungi. P.aeruginosa $80(45.9 \%)$ was the dominant isolate, followed by S.aureus 46(26.4\%) including 10 isolates of MRSA. Tammoy Deb et al. ${ }^{8}$ in 2012. In a study of the Bacteriological Profile of CSOM in Agartala, suggested that gram negative bacteria is the commonest involved in CSOM in part of north east India. Kabir MS 7 in 2012. In a study Pattern of CSOM, among 110 patients, Pseudomonas aeruginosa is the most common organism (43.68\%) isolated in pure culture followed by S.aureus $27.59 \%, \mathrm{v}$ E.Coli $10.35 \%$, Klebsiella spp. $9.19 \%$, proteus sp. $8.04 \%$.

\section{CONCLUSION}

The commonest organism found in the culture is P.Aeruginosa ( $42 \%$ ) followed by S.aureus (21\%). The next comes Klebsiella(9\%), Proteus and CNSA (5\%) each and Acinetobacter and E.coli (4\%) each. There is no Growth in $(8 \%)$ and $(2 \%)$ are commensals. The organism isolated in CSOM shows maximum sensitivity to Gentamicin followed by Ciprofloxacin, amikacin, Cefotaxime. It is less sensitive to Doxycycline, Norfloxacin, Tobramycin, Roxithromycin, Cefazolin, chloramphenicol.

\section{REFERENCES}

1. Mills RP. Management of CSOM. In: Booth B. Ed. ScottBrown's Otolaryngology $6^{\text {th }}$ Edn. Vol. 3 ButterworthHeinemann: Oxford: 1997:3/70/3pp.

2. Joklik WK. Willett HP, Amos DB. Willeft CM. Zinsser Microbiology $20^{\text {th }}$ Edn. Appleton and Large: New Walk: Connecticut: 1992 .

3. Ananthanaryan R. Panikar CKJ Text Book of Microbiology $5^{\text {th }}$ Edn (Revised) Orient Longman Ltd: Chennai:1998

4. Collee JG, Marmion BP, Fraser AG. Simmons A, Mackie and McCarney. Practical Medical Microbiology $14^{\text {th }}$ Edn. Churchill Livingstone: New York: 19963.

5. J. Gulati. P.L. Tendon, Waryan Singh, A.S. Bais, Study of Bacterial flora in CSOM. Indian Journal of Otolaryngology December 1969, volume 21, Issue 4, Pg 198-202.

6. Poorey VK. Lyer A Study of Bacterial flora in CSOM and its clinical significance. Indian Journal of Otolaryngology and Head and Neck Surgery 2002; 54:9 1-95

7. Kabir MS in 2012, Joarder aH. Ekramuddaula FM. Uddin. MM. Islam Mr. Habib MA. Pattern of CsOM Mymensingh Med J. 2012 apr:21(2):270-5.

8. BM Ahmad, MT Kadi. CSOM in Gombe, Nigeria. Nigerian Journal of surgical Research Vol.5(1)and2)2003:120-123.

9. Fliss DM. Dagan R. Meidan N.Leiberman A. Aerobic Bacteriology of CSOM without cholesteatoma in Children, Ann Otol Rhinol Laryngol 1992:101:866-869.

10. Atanu Nandy, P.S. Mallya. K. Sivarajan, CsOM-A bacteriological study Indian Journal of Otolaryngology September 1991, volume 43, Issue 3, 99 136-138.

11. Grevel R.S. Ram S. Bacteriological patterns of CSOm, in Ludiana, Indian J Med Sei (serial online) 1996 (cited 2012 New 20);50:192-5.

12. Fatna a. Assiry S. Siray ZM. Microbiological Exaluation and Aspects on Management of CSOM in Riyadh. Indian Journal of Orology 1998; 4(3): 115-120.

13. Indudharn r. Haq JA, aiyar S. antibiotics in CSOM: A Bacteriological Study. Ann Otol Rhinol Laryngol 1999; 108: 440-445.

14. Kamran Iqbal. Muhammad Ismail Khan, Laqnam satti. Microbiology of CSOM experience at dera ismail khan. Gomal journal of medical sciences July-december 2011, vol. 9. No.2

Source of Support: None Declared Conflict of Interest: None Declared 